\title{
Recalibration of the 5-parameter MRK equation of state for C-O-H fluids under upper mantle conditions and some experimental tests
}

\author{
Taylor, W.R. ${ }^{1}$, and Matveev, S. ${ }^{2}$
}

${ }^{1}$ R.S.E.S., Australian National University, Canberra, A.C.T. 0200, Australia

${ }^{2}$ Institut für Mineralogie und Geochemie, Universität zu Köln, Zülpicher Str. 49b, 50674 Köln, Germany (formerly Max Planck Institute, Mainz, Germany)

An extensive series of experiments in the system C-O-H fluid + graphite at $2.4 \mathrm{GPa}$ and $1000^{\circ} \mathrm{C}$ was undertaken by Matveev et. al. (1997). The fluids were either unbuffered or were buffered by various metal-oxide oxygen buffers and fluid analyses were undertaken by a capsule piercing-gas chromatography technique. Numerous experimental tests showed that the fluid analyses reflected those of high-P,T equilibrium, i.e. quench modification processes were generally not significant provided maximum quench rates were employed. One goal of these experiments was to develop an equation of state (EOS), or modify an existing EOS, for supercritical $\mathrm{C}-\mathrm{O}-\mathrm{H}$ fluids in order to better estimate species activities and distributions under upper mantle $\mathrm{P}, \mathrm{T}, \mathrm{fO}_{2}$ conditions.

We have compared a number of equations of state for supercritical C-O-H fluids and found that the 5-parameter Modified-Redlich-Kwong (5PMRK) EOS of Taylor (1989), using standard mixing rules, provides the best fit to the experimental data. The 5PMRK EOS has the form:

$$
\begin{aligned}
& P=\left[R \cdot T \cdot\left(1+y+y^{2}-y^{3}\right)\right] /\left[V_{m} \cdot(1-y)^{3}\right]-\left[\left(a_{1}+a_{2} / V_{m}+a_{3} / V_{m^{2}}\right)\right] /\left[T^{1 / 2} \cdot V_{m} \cdot\left(V_{m}+b\right)\right] \\
& \mathrm{b}=\mathrm{b}_{1}+\mathrm{b}_{2} / \mathrm{T} \quad \mathrm{V}_{\mathrm{m}}=\text { molar volume }\left(\mathrm{cm}^{3} \mathrm{~mol}^{-1}\right) \quad \mathrm{T}=\text { temperature }(\mathrm{K}) \\
& \mathrm{y}=\mathrm{b} / 4 \mathrm{~V}_{\mathrm{m}} \quad \mathrm{P}=\text { pressure (bar) } \quad \mathrm{R}=83.143 \mathrm{~cm}^{3} \mathrm{barK}^{-1} \mathrm{~mol}^{-1} \\
& \mathrm{a}=3 \text {-term attractive MRK parameter } \quad \mathrm{b}=2 \text {-term repulsive MRK parameter }
\end{aligned}
$$

Although good agreement was found for major fluid species such as $\mathrm{H}_{2} \mathrm{O}$ and $\mathrm{CH}_{4}$, calculated abundances for the minor species $\mathrm{H}_{2}$ and $\mathrm{C}_{2} \mathrm{H}_{6}$ were found to be too low by $\sim 25 \%$. In an attempt to achieve better agreement with the experimental data, but by a method independent of the experiments, the MRK parameters for both $\mathrm{H}_{2}$ and $\mathrm{C}_{2} \mathrm{H}_{6}$ were refitted using molar volume constraints for the pure fluids provided by shock wave data and molecular dynamics simulations. This data was not available at the time of the original calibration of the 5PMRK. The recalibration was performed using an iterative Monte Carlo fitting routine and yielded the following results:

TABLE 1. 5PMRK Parameters

\begin{tabular}{llllll}
\hline Species & $\mathrm{b}_{1}$ & $\mathrm{~b}_{2}$ & $\mathrm{a}_{1} / 10^{7}$ & $\mathrm{a}_{2} / 10^{8}$ & $\mathrm{a}_{3} / 10^{9}$ \\
\hline $\mathrm{H}_{2} \mathrm{O}$ & 21.34 & 5420 & 13.29 & 25.41 & 19.15 \\
$\mathrm{CO}_{2}$ & 45.53 & 10730 & 12.87 & 11.22 & 444.3 \\
$\mathrm{CO}$ & 40.11 & 3769 & 3.869 & 6.45 & 8.008 \\
$\mathrm{H}_{2}$ & 12.18 & 2825 & 0.0664 & 0.0814 & 0.1045 \\
$\mathrm{CH}_{4}$ & 43.38 & 7409 & 6.742 & 28.93 & 97.49 \\
$\mathrm{C}_{2} \mathrm{H}_{6}$ & 74.38 & 7520 & 21.1 & 61.5 & 163.0 \\
\hline
\end{tabular}

Species distributions were then calculated with the Fortran77 program 'GFLUID6' (available from the authors on request). For the most robust experiments buffered at IW, and for a number of unbuffered experiments, agreement was found to be excellent (Table 2). Good agreement was also obtained with the lower P, T experiments of Jakobsson and Oskarsson 
(1990). Of the various MRK equations available in the literature, the recalibrated 5PMRK gives the best agreement with experiment for $\mathrm{CH}_{4}-\mathrm{H}_{2} \mathrm{O}$-rich fluids and should be suitable for extrapolation to pressure of at least $5 \mathrm{GPa}$.

TABLE 2. Comparison of Experimental and Calculated C-O-H (+graphite) Fluids $\dagger$

\begin{tabular}{|c|c|c|c|c|c|c|c|c|c|}
\hline & $\operatorname{expt}^{\mathrm{a}}$ & $1 \sigma$ & calc. & $\operatorname{expt}^{\mathrm{a}}$ & $1 \sigma$ & calc. & $\operatorname{expt}^{b}$ & $1 \sigma$ & calc. \\
\hline $\begin{array}{l}\mathrm{P}(\mathrm{GPa}) \\
\mathrm{T}(\mathrm{K}) \\
\log \left(\mathrm{fO}_{2}\right) \\
\text { no. analyses }\end{array}$ & $\begin{array}{l}2.4 \\
1273 \\
\mathrm{IW} \\
\mathrm{n}=5\end{array}$ & & $\begin{array}{c}2.4 \\
1273 \\
-13.75\end{array}$ & $\begin{array}{l}2.4 \\
1273 \\
\text { none } \\
n=2\end{array}$ & & $\begin{array}{l}2.4 \\
1273 \\
-12.0\end{array}$ & $\begin{array}{l}1.5 \\
1473 \\
\text { IW } \\
n=4\end{array}$ & & $\begin{array}{c}1.5 \\
1473 \\
-11.34\end{array}$ \\
\hline $\begin{array}{l}\mathrm{H}_{2} \mathrm{O} \\
\mathrm{CO}_{2} \\
\mathrm{CO} \\
\mathrm{H}_{2} \\
\mathrm{CH}_{4} \\
\mathrm{C}_{2} \mathrm{H}_{6}\end{array}$ & $\begin{array}{l}11.7 \\
\text { bdl } \\
\text { bdl } \\
5.1 \\
81.4 \\
1.9\end{array}$ & $\begin{array}{l}.4 \\
.8 \\
.2\end{array}$ & $\begin{array}{l}11.5 \\
<0.1 \\
<0.1 \\
4.9 \\
81.7 \\
1.9\end{array}$ & $\begin{array}{l}88.3 \\
0.17 \\
\text { bdl } \\
1.8 \\
9.7 \\
0.12\end{array}$ & $\begin{array}{l}.1 \\
2.2 \\
.03\end{array}$ & $\begin{array}{l}88.4 \\
0.16 \\
<0.1 \\
1.8 \\
9.6 \\
0.05\end{array}$ & $\begin{array}{l}21.8 \\
0.11 \\
0.38 \\
11.3 \\
65.3 \\
1.03\end{array}$ & $\begin{array}{l}1.1 \\
.02 \\
.05 \\
1.0 \\
1.5 \\
.06\end{array}$ & $\begin{array}{l}20.7 \\
0.14 \\
0.25 \\
11.2 \\
66.3 \\
1.42\end{array}$ \\
\hline
\end{tabular}

† Fluid compositions in mole\%; bdl = below detection limit.

a Matveev et al., 1997, and unpubl. experimental data.

b Jakobsson and Oskarsson (1990)

\section{References}

Jakobsson, S. and Oskarsson, N., 1990, Experimental determination of fluid compositions in the system C-O-H at high P and T and low fO2. Geochim. Cosmochim. Acta, 54, p. 355-362.

Matveev, S., Ballhaus, C., Fricke, K., Truckenbrodt, J., and Ziegenbein, D., 1997, Volatiles in the Earth's mantle I. Synthesis of CHO fluids at $1273 \mathrm{~K}$ and $2.4 \mathrm{GPa}$. Geochim. Cosmochim. Acta, in press.

Taylor, W.R., 1989, A reappraisal of the nature of fluids included by diamond - a window to deep-seated mantle conditions and redox processes. Univ. West. Austr. Special Publ., 23, p.333-349. 